\title{
Research on the construct of the innovative ecosystem and its operating regime of the technology enterprises in Xi'an
}

\author{
Wang Yan \\ Xi’an International University, Xi'an Shaanxi, 710077
}

Keywords: Xi’an, Technology Enterprise, Innovative Ecosystem, Operative Regime

\begin{abstract}
In the recent industrial and economic developmental planning of China, to support the development of the high-tech industry has been put forward; the local government also should play a leading role on the development of the high-tech industry. For example, the government should support the technology enterprises and construct the good developmental ecosystem. Although the municipal government of Xi'an is promoting the development of the technology enterprises, but there are still a lot of outstanding problems, and there also are no the sound and effective ecosystem and the operative regime. This thesis researches the construction of the innovative ecosystem and the operative regime of the technology enterprises in Xi'an, analyzes some present problems, and puts forward some relevant countermeasures and suggestions.
\end{abstract}

To the innovative development of the technology enterprises, the government plays a very important role during this process, the government should provide a very good innovative ecosystem to the enterprises, at the some time, the government should construct the perfect operative regime for the technology enterprises, these are very important to the innovative development of the technology enterprises. Therefore, from this point of view, the Xi'an municipal government should construct the sound innovative ecosystem and the sound operative regime and the corresponding system, and coordinate the relationship between the relevant departments and the enterprises, so as to improve the innovative development of the technology enterprises.

\section{The significance of constructing the innovative ecosystem and the operative regime for the technology enterprises}

The innovative ecosystem of the technology enterprise means the overall circumstance of the enterprises' innovative activities; it includes the responding policy circumstance, market circumstance, human resource circumstance, and so on. The innovative ecosystem is very important to the innovative activities of the enterprises; it influences the results of the enterprises' innovative activities. The government should play a leading role on the construction of the technology enterprises' innovative ecosystem and the operative regime, so as to ensure the innovative activities of the technology enterprise could be implemented well, and promote the innovation activities and the development of the technology enterprises. From this point of view, to construct a sound innovative ecosystem of the technology enterprises is an important foundation for achieving the healthy and constant development of the enterprises, the policy circumstance, the market circumstance, and the human resource circumstance all are very important to the development of the enterprises. By constructing the perfect innovative ecosystem and the operative regime, the government could provide the necessary support to the technology enterprises for their innovation activities and further development; it also could promote the optimization and upgrading of local industrial structure. Therefore, to construct the innovative ecosystem and the operative regime is very important to the innovative development of the technology enterprises. 


\section{The Problems on Xi'an technology enterprises' Operative Regime of the Innovative Ecosystem}

We must notice that there are still a lot of outstanding problems on the construction of the innovative ecosystem and the operative regime, such as it is lack of the unified and sound strategic planning, the relevant departments do not coordinate well, and it is lack of the responding encouraging measures.

First of all, according to the present developmental situation of the technology enterprises in Xi'an, although the local government has carried out some relevant policies, but these policies have not achieved the sound actual effect, and the municipal government of Xi'an has not play a good role which it should be. One of the outstanding problems is the government has not make a unified and sound strategic planning, especially the long-term strategic planning, so that it brings some adverse effects to the technology enterprises in Xi'an. From this point of view, the technology enterprises in Xi'an need the good developmental circumstance badly, while this circumstance is constructed by the local government. However, the enterprises are lack of this kind of circumstance during the process of their innovations, and the local government also has not drafted the unified and sound strategic planning for their innovative development. Therefore, because the technology enterprises are lack of the unified and sound strategic planning, so that a lot of supporting policies and countermeasures can not be implemented well, and the effects of the current policies declines.

For constructing a sound innovative ecosystem of the technology enterprise in Xi'an, the relevant governmental departments should coordinate the corresponding affairs actively and well, and achieve the effective and coordinating cooperation between the enterprises and the government; while according to the actual construction situation of the innovative ecosystem of the technology enterprises in Xi'an, the relevant departments haven't cooperated well and actively, these decline the efficiency of the operative regime. For example, the operation of the innovative ecosystem involves a lot of governmental departments, such as industrial and commercial bureau, tax bureau; financial institutions, etc. Only these departments cooperate with the others well could provide the efficient and high-quality services to the technology enterprises, so as to promote the innovative development of the enterprises. But, the local government hasn't carried out effective countermeasures, the leading department also hasn't fulfilled its functions, and the involved departments also haven't cooperated well, to sum up, these bring lots of diverse effects to the innovative development of the technology enterprises in Xi'an.

The local government has not effective incentive measure is an outstanding problem that declines the construction of the innovative ecosystem of the technology enterprises. During the process of the construction, although the government provides some supporting policies to the enterprises, but the policies are still not enough so that they could not support the technology enterprises well, and these policies also can not attract the enterprises to carry out innovative activities. To the construction of the innovative ecosystem of the technology enterprise, the incentive measure is a very important part. The government should provide the supports or the premiums to the enterprises for encouraging their innovative activities. For example, the tax favor or other kind of financial support could encourage and attract the enterprises to innovate further more. But we must notice that there are no enough incentive measures, and the incentive measures are also defective. In general, although the local government has carried out some incentive measures, but the measures are not enough, and these measures haven't promoted the innovative development of the technology enterprises well.

\section{The countermeasures for the construction of the innovative ecosystem and the operative regime of the technology enterprises in Xi'an}

To solve the problems that are existing during the construction process of the innovative ecosystem of the technology enterprises in Xi'an, the local government should adopt some corresponding countermeasures, such as making the unified and sound strategic planning of the construction of the innovative ecosystem and the operative regime, coordinating the relationship 
between the relevant departments and the technology enterprises, and strengthening the incentive measures for the innovative activities of the technology enterprises.

During the construction process of the Xi'an technology enterprises' operative regime of the innovative ecosystem, the local government should play a leading role, and undertake the corresponding duty, so as to make the unified and sound strategic planning of the innovative ecosystem's operative regime, this is very important to the innovative development of the technology enterprises in Xi'an. To make the unified and sound operative regime of the innovative ecosystem for the technology enterprises, the local government should consider both the features of the technology enterprises and the realistic situation of Xi'an, and play an indemnificatory role for the innovative development of the technology enterprises. For example, to make the long-term policy and the scientific developmental objective for the technology enterprises, especially to optimize and upgrade the industrial structure and to integrate the optimization of the industrial structure with the innovative development of the enterprises so as to achieve the sound developmental results. So to speak, to make the unified and sound strategic planning of the technology enterprises' operative regime of the innovative ecosystem, the government should not only consider the actual developmental situation of the technology enterprises in Xi'an, but also consider the features of the technology enterprises on the innovative development, and then make the corresponding developmental planning with a certain reason.

We must notice that the relevant governmental departments should support the technology enterprises a lot on their innovative development, this support is also necessary to the construction of the operative regime of the enterprises' innovative ecosystem. The government should clarify the duty and responsibility of the relevant departments on the innovative activities of the technology enterprises, so that the departments could cooperate well with the technology enterprises. During this process, the leading department also should take the best of their leading role, for example, the leading department could coordinate the relationship between the enterprises and the other departments such as the tax bureau, industrial and commercial bureau, science and technology bureau, and so on. When the enterprises meet some problems, the relevant departments should solve the problems as soon as possible. In general, to coordinate the relationship between the relevant departments and the technology enterprises is very important to the operative efficiency of the innovative ecosystem; the relevant governmental departments should know well about the present outstanding problems and the weakness, so as to adopt some effective countermeasures to promote the innovative development of the technology enterprises in Xi'an.

To strengthen the incentive measures for the innovative activities of the technology enterprise is a very important part for constructing a sound operative regime of innovative ecosystem, so the relevant governmental departments should know well about this issue, not only make the relevant policies, but also strengthen the incentive measures. For example, the tax bureau could reduce or exempt some tax payments to the enterprises that do well in the innovative activities, so as to encourage the technology enterprises to innovate much better. Incentive measure is a very effective way to promote the innovative development of the technology enterprises, if there is a great policy support, it would motivate the technology enterprises to develop their innovative abilities further more and launch more innovative activities.

\section{Conclusion}

By researching the construction of the innovative ecosystem and the operative regime of the technology enterprises in Xi'an, this thesis finds out that there are still some outstanding problems on the construction of the innovative ecosystem and the operative regime of the technology enterprises in Xi'an, such as there is no unified and sound strategic planning, it is difficult to coordinate the relationship between the relevant governmental departments and the technology enterprises, and it is lack of effective incentive regime, etc. The local government should make the unified and perfect strategic planning on constructing the innovative ecosystem and the operative regime, coordinate the relationship between the relevant apartments and the technology enterprises, and strengthen the incentive measures for the innovative activities of technology enterprises. 


\section{Acknowledgements}

Project of the Annual Social Science Planning Funds of Xi’an, 2017.

Project Title: Research on the Construct of the Innovative Ecosystem and Its Operative Regime of the Technology-oriented Enterprise in Xi'an.

Project No.: 17IN06.

\section{References}

[1] Cui Jie. Research on the Technology Enterprises' Operative Regime of the Innovative Ecosystem[J]. Science and Technology, 2017, (29):162-163.

[2] Chen Wei. Analysis on the Innovative Ecosystem Management Regime that Base on the Viewpoint of the Medium and Small Enterprises [J]. Journal of Commercial Economics, 2017, (11):98-99.

[3] Xu Ling, Yu Zhen. Study on Present Situation and Influencing Factors of Shaanxi Province High-tech Companies Technology Innovation Models [J]. Value Engineering, 2012, (32):156-157. 